\title{
Higher bioavailability of isoflavones after a single ingestion of a soya-based supplement than a soya-based food in young healthy males
}

\author{
Sébastien Vergne ${ }^{1,2}$, Catherine Bennetau-Pelissero ${ }^{1}$, Valérie Lamothe ${ }^{1}$, Philippe Chantre ${ }^{2}$, Mylène Potier ${ }^{1}$, \\ Julien Asselineau ${ }^{3}$, Paul Perez ${ }^{3}$, Marlène Durand ${ }^{4}$, Nicholas Moore ${ }^{5}$ and Patrick Sauvant ${ }^{1 *}$ \\ ${ }^{1}$ ENITA de Bordeaux, Unité Micronutriments, Reproduction, Santé, Bordeaux, France \\ ${ }^{2}$ Arkopharma, Laboratoires Pharmaceutiques, Carros, France \\ ${ }^{3}$ CHU de Bordeaux, Unité de Soutien Méthodologique à la Recherche clinique et épidémiologique, Bordeaux, France \\ ${ }^{4}$ Centre d'Investigation Clinique (CIC), INSERM - CHU de Bordeaux, France \\ ${ }^{5}$ Université Victor Segalen, Département de Pharmacologie, INSERM U657 Bordeaux, France
}

(Received 8 December 2006 - Revised 25 June 2007 - Accepted 26 June 2007)

Soya isoflavones, genistein and daidzein, are the focus of numerous studies investigating their potential effects on health and results remain controversial. Bioavailability is clearly a crucial factor influencing their bioefficacy and could explain these discrepancies. This study aimed at assessing: (1) the isoflavone content of sixty-nine European soya-derivative products sold on the French market; (2) the bioavailability of isoflavones comparing supplement with food. Twelve healthy volunteers were recruited in a randomized two-way crossover trial and received $35 \mathrm{mg}$ isoflavones equivalent aglycone either through supplements or through cheese, both containing different patterns of isoflavone conjugates and different daidzein:genistein ratios. A specific ELISA method was used to assess the plasma and urinary concentrations of isoflavones and thus the pharmacokinetic parameters, which were then normalized to $\mathrm{mg}$ of each isoflavone ingested. Results showed that the normalized Cmax of daidzein $(P=0.002)$ and similarly the normalized $\mathrm{AUC}_{0 \rightarrow \infty}$ and $C_{\max }$ of genistein $(P=0.002)$ from soya-based capsules were higher than that from soya-based cheese. In conclusion, this work completes studies on isoflavone bioavailability and presents new data regarding isoflavone concentrations in soya-derivative products. Assuming that isoflavone conjugation patterns do not influence isoflavone bioavailability, this study shows that isoflavones contained in capsules are more bioavailable than those contained in soya-based cheese. Although the supplement is more bioavailable, the relative importance of this is difficult to interpret as there is little evidence that supplements are biologically active in human subjects to date and further studies will be necessary for this specific supplement to prove its efficacy.

Soya: Isoflavones: Bioavailability

The role of dietary flavonoids in the prevention of several chronic diseases is the subject of intense research interest and soya isoflavones have been the focus of particular attention ${ }^{1,2}$. To exert their action on health, micronutrients, such as soya isoflavones, have to be bioavailable. There have been major advances in the past few years regarding the absorption and the metabolism of soya isoflavones ${ }^{3}$ and it is apparent that soya isoflavones are sufficiently absorbed to exert biological effects ${ }^{4}$, reaching micromolar concentrations in blood ${ }^{3}$.

Isoflavones are mainly present as glucoside conjugates in most commercially available soya-containing products, except products resulting from soya fermentation, such as tempeh, tofu or several soya-based cheeses ${ }^{5}$. After ingestion, isoflavones are not absorbed in this form; their absorption requires hydrolysis of the sugar moiety of these compounds by gastric acid ${ }^{6,7}$ and intestinal and bacterial $\beta$-glucosidases $^{8,9}$. A proportion of isoflavones are then absorbed and conjugated again mainly into glucuronic acid and, to a lesser extent, into sulphuric acid, increasing their solubility and consequently their ability to circulate in plasma. Another proportion of the isoflavones are metabolized by intestinal bacteria into other metabolites, such as equol ${ }^{10}$ or $o$-desmethylangolensin ${ }^{11}$.

Isoflavones are abundant in soya and soya-derivative products such as dietary supplements. The range of different dietary soya-based supplements available through chemists, health-food shops and supermarkets has been growing manyfold over the last decade in Western countries ${ }^{12}$. In previous studies, the bioavailability of isoflavones was investigated using glycosilated pure compounds or aglycone pure compounds ${ }^{13-15}$ or single soya-based foods ${ }^{16,17}$. Interestingly, four recent articles aimed at studying factors affecting the bioavailability of isoflavones and especially compared different soya food matrices ${ }^{18-21}$. Finally, it still remains essential to understand whether serum and urine levels are similar following consumption of a known dose of isoflavones, which are present in different food matrices ${ }^{19}$.

In the present study, the isoflavone content of sixty-nine soya-derivative products, available on the French and European commercial market, were analysed using an ELISA 
method. Isoflavones were measured after the hydrolysis of the sugar moiety, i.e. in their aglycone forms. The data on the concentrations of daidzein and genistein in foodstuffs reported in this article can be used in future studies to assess the dietary intake of these compounds and their impact on health in epidemiological studies. Moreover, the current study examined the apparent bioavailability of isoflavones comparing soyabased supplements with soya-based cheese. A group of twelve healthy Caucasian males were recruited to perform a crossover trial, in which each volunteer randomly consumed the two soya-derivative products, containing $35 \mathrm{mg}$ soya isoflavones, equivalent aglycone.

\section{Subjects and methods}

\section{Soya-based products}

The commercial soya-derivative products were obtained from chemists, supermarkets or special organic food shops depending on the distribution circuits. For each trademark, a sample was used for the analysis and the measurements were performed in triplicate.

Two popular soya-based products were used to compare apparent bioavailability of isoflavones. A soya-based supplement in capsule form was provided by Arkopharma, Pharmaceutical Laboratories (Carros, France) and a soya-based cheese was provided by Le Sojami (Agen, France). Before the clinical trial, each formulation was assessed for daidzein and genistein content measured with an ELISA method and expressed in aglycone equivalents. The amount of each soya-based food consumed by the subjects was adjusted to ensure that the total intake of isoflavones, equivalent aglycone, was similar throughout the study.

The chemical composition of the isoflavones, contained in the two particular food products tested for isoflavone bioavailability comparison, was assessed using the extraction and HPLC methods described by Murphy et al. ${ }^{22}$. Furthermore, the nutritional composition of these two soya-based items, based on the information supplied by the manufacturers, is given in Table 1.

Table 1. Food composition of the two soya-based products used for the bioavailability study $\dagger$

\begin{tabular}{|c|c|c|}
\hline & $\begin{array}{l}\text { Portion of soya-based } \\
\text { cheese }(56 \mathrm{~g})\end{array}$ & $\begin{array}{c}\text { Soya-based } \\
\text { supplement } \\
\text { (four pills) }\end{array}$ \\
\hline Energy (kJ) & 370 & $16 \cdot 8$ \\
\hline Protein $(\mathrm{g})$ & 5.77 & 0.26 \\
\hline Carbohydrates (g) & 0.44 & 0.52 \\
\hline Lipids (g) & 7.06 & 0.10 \\
\hline Saturated $(g)$ & 1.23 & ND \\
\hline Monounsaturated (g) & 3.00 & ND \\
\hline Polyunsaturated (g) & $2 \cdot 70$ & ND \\
\hline Cholesterol (g) & 0 & ND \\
\hline Fibres (g) & 0.22 & ND \\
\hline Isoflavones* (mg) & 35.00 & $35 \cdot 00$ \\
\hline Daidzein* (mg) & $15 \cdot 78$ & $28 \cdot 24$ \\
\hline Genistein* (mg) & $19 \cdot 22$ & $6 \cdot 76$ \\
\hline
\end{tabular}

ND, Not determined.

*Expressed as aglycone equivalent.

†For details of procedures, see Subjects and methods.

\section{Study subjects}

Twelve healthy male Caucasian volunteers, aged 20 to 29 years with BMI between 20 to $25 \mathrm{~kg} / \mathrm{m}^{2}$, gave informed consent to enter the present study. Prior to the study, all subjects underwent a full clinical examination. None of the subjects had allergy or intolerance to soya. The subjects had to abstain from consuming any drugs, especially antibiotics, for at least $30 \mathrm{~d}$ prior to the beginning of the study and during the study. Soya foods and their derivatives were prohibited for $10 \mathrm{~d}$ prior to and during the study. The main foods containing polyphenols, such as red fruits, red wine, chocolates, tea or coffee, were prohibited for $3 \mathrm{~d}$ prior to the beginning of the study and during the study. The study was performed at the Clinical Investigation Center (Haut-Levêque Hospital, Pessac, France) and was approved by the local Medical Ethics Committee (Comité Consultatif pour la Protection des Personnes se prêtant à des Recherches Biomédicales, CCPPRB, Bordeaux A, France). During the kinetic analysis, meals were controlled by a dietitian and were strictly the same for every subject. No adverse effect in relation to the ingestion of the soya-based products was reported.

\section{Design of the study}

The design was a randomized, two-way crossover study, involving twelve young male volunteers, who were fed a soya-derivative product containing $35 \mathrm{mg}$ isoflavones, as either supplements or cheese. On the basis of the $35 \mathrm{mg}$ total aglycone isoflavones, each subject consumed four pills of Phytosoya ${ }^{\circledR}$ (Arkopharma), i.e. $28.24 \mathrm{mg}$ daidzein and $6.76 \mathrm{mg}$ genistein, and $56 \mathrm{~g}$ cheese Le Tartimi ${ }^{\circledR}$ (Le Sojami), i.e. $15.78 \mathrm{mg}$ daidzein and $19.22 \mathrm{mg}$ genistein. Volunteers were hospitalized at 12.00 hours for a $24 \mathrm{~h}$ period and randomly received a single dose of either Phytosoya ${ }^{\circledR}$ or soyabased cheese. After intake of the soya-based capsules or cheese, volunteers had lunch at 12.00 hours, dinner at 19.00 hours and breakfast at 07.00 hours the following morning. After a 2-week wash-out period, the study was repeated in the same conditions to complete the crossover design. Blood samples $(10 \mathrm{ml})$ were drawn into Vacutainer ${ }^{\circledR}$ glass tubes (Becton Dickinson, Le Pont-De-Claix, France) containing heparin and lithium as anticoagulants, through an indwelling cannula, before (0) and 2, 4, 6, 8, 12, 18, 24 and $48 \mathrm{~h}$ after the intake of soya-based products. Plasma samples were prepared by centrifugation at $5000 \mathrm{~g}, 5 \mathrm{~min}, 4^{\circ} \mathrm{C}$ and stored frozen at $-20^{\circ} \mathrm{C}$ until further analysis. Urinary samples were collected before $(0)$ and $6,12,18,24 \mathrm{~h}$ after the ingestion of soya-derivative products. During the second day of the experiment, volunteers were instructed to collect all their urine in plastic bottles containing ascorbic acid $(1 \mathrm{~g} / \mathrm{l})$. The volume of each micturition was measured and a $10 \mathrm{ml}$ aliquot of each sample was removed and stored at $-20^{\circ} \mathrm{C}$ until analysis.

\section{Serum and urinary isoflavone analysis}

Daidzein, equol and genistein concentrations in masked blood samples were measured by the ELISA method previously described $^{23,24}$. Briefly, samples were first digested for $48 \mathrm{~h}$ with $\beta$-glucuronidase aryl sulfatase from Helix pomatia 
(Roche Diagnostics, Meylan, France) in acetate buffer, pH 5. Aglycone isoflavones were then extracted three times with acidified ethyl actetate buffer (Fluka, Buchs, Switzerland). Finally, assays were performed following the classical indirect competitive ELISA using primary rabbit antibodies for daidzein, equol and genistein developed in the laboratory ${ }^{23,25}$. The secondary antibody was polyclonal swine anti-rabbit $\mathrm{IgG}$, complexed with a peroxydase enzyme (Dako, Trappes, France) used with o-phenylenediamine as a substrate for revelation. Optical density (OD) was read at $490 \mathrm{~nm}$ (MRX II; Dynex Technologies, Issy-les-Moulineaux, France) and the concentration of isoflavones was determined from standard curves of each isoflavone $\left(r^{2} \geq 0.99\right)$. Hydrolysis and extractions were checked against external standards. The inter-assay variation is $12.8 \%$ for daidzein, $13.1 \%$ for genistein and $13.6 \%$ for equol measured comparing the same sample on ten different plates. The intra-assay variation $5 \%$ for daidzein, $4.8 \%$ for genistein and $5 \%$ for equol measured on the same sample assayed twelve times on the same plate. The samples are run randomly on plates together with an assay control sample (same sample on each plate). The sensitivity of the assays given as the mid point of the standard curve is $15.6 \mathrm{ng} / \mathrm{ml}$ for daidzein and genistein and $10 \mathrm{ng} / \mathrm{ml}$ for equol. The detection limits of this specific analytical method are $3.9 \mathrm{ng} / \mathrm{ml}$ for daidzein and for genistein and $2.5 \mathrm{ng} / \mathrm{ml}$ for equol and have been improved from the previously reported study $^{24}$. The technique was validated against the HPLC method coupled to a UV detector for the supplements and foods and coupled to a cool array detector for biological fluid samples ${ }^{26}$.

\section{Determination of the serum and urinary isoflavone} pharmacokinetics

All pharmacokinetic parameters were performed by the pharmacokinetic software PK-FIT version 1.2 (RDPP, Montpellier, France). A non-compartmental pharmacokinetic analysis was used to analyse plasma isoflavone concentration-time data. The maximum observed concentration $\left(C_{\max }\right)$ and time to reach peak concentration $\left(T_{\max }\right)$ parameters were obtained directly from experimental observations without interpolation. The terminal slope $\left(K_{\mathrm{e}}\right)$ of the concentration-time curve was determined by log-linear regression. Elimination half-life $\left(T_{\frac{1}{2}}\right)$ of the terminal log-linear phase was calculated following the equation $0 \cdot 693 / K_{\mathrm{e}}$. The area under the plasma concentration-time curve was extrapolated to infinity $\left(\mathrm{AUC}_{0 \rightarrow \infty}\right)$. It was determined by summing the areas from time 0 to the time of the last quantifiable concentration $(t)$ (obtained by trapezoidal and log-trapezoidal methods: $\left.\mathrm{AUC}_{0 \rightarrow t}\right)$ and the extrapolated area from $\mathrm{t}$ to infinity $\left(\mathrm{AUC}_{t \rightarrow \infty}\right)$. The extrapolated area was determined by dividing the last detectable concentration by the slope of the terminal log-linear phase. To ensure that statistical comparisons were valid, $C_{\max }$ and $\mathrm{AUC}_{0 \rightarrow \infty}$ values for daidzein and genistein were dose-adjusted to take into account the differences in the proportion of isoflavones within each soya food product.

\section{Statistical analysis}

All data are expressed as means and standard deviations. Comparison of the pharmacokinetic parameters of each isoflavone was based on a crossover analysis using intra-subject comparisons of the two soya-based products. It consisted of a two-step strategy as proposed by Grizzle ${ }^{27}$. First, the interaction between the two soya-based products and the intake period was studied. If significant at a nominal significance level $0 \cdot 10$, the comparison between the two soya-based products only used the data from the first intake period. Otherwise, comparison between the two soya-based products was performed using the two intake periods. All comparisons used the Wilcoxon sign rank test. Except for the interaction analysis, all tests were considered statistically significant at a $P$ value $<0.05$.

Statistical analyses between the mean urinary excretions of isoflavones, according to the two soya-based products ingested, were performed by Student's $t$ test. Differences were considered significant at $P<0.05$.

\section{Results}

\section{Isoflavone contents in commercial soya foods}

Tables 2 and 3 present respectively the isoflavone content assessed by ELISA in forty-nine soya-based supplements and in twenty soya-based foods available on the French and European market. From these tables, it can be observed that content of isoflavones can vary greatly according to the brand. Indeed, consumers can ingest from 0.07 to $92.8 \mathrm{mg}$ aglycone isoflavones per $\mathrm{d}$, as specified by the manufacturers on the product packaging. Of the sixty-nine soya food products reported in this article, forty-six exhibit a major content of genistein in comparison with daidzein. Despite the lower concentrations of isoflavones in soya foods compared with soya-based capsules, isoflavone level intakes are of the same order of magnitude due to the size of the food portions ingested.

\section{Isoflavone contents in foods used for clinical study}

Fig. 1(A),(B) represents the HPLC chromatograms corresponding to the soya-based products ingested during the clinical study. Isoflavones are mainly present as glycoside forms in the capsules: $97.4 \%$ daidzein and $98.1 \%$ genistein ingested were in glycoside form. For cheese, a larger proportion of aglycone isoflavones was measured. It was found that $57.8 \%$ daidzein and $43.7 \%$ genistein ingested were in glycoside form.

\section{Serum kinetics of isoflavones}

The mean plasma concentration time-profiles of daidzein and genistein from 0 to $48 \mathrm{~h}$ after a single oral dose of both soyabased foodstuffs are represented in Fig. 2. At baseline, patients had no detectable concentrations of genistein and daidzein. The kinetics of both isoflavones present a similar pattern. Absorption is biphasic and occurs between 0 and $8 \mathrm{~h}$. A first peak of daidzein concentration was reached at $2 \mathrm{~h}$ for both soya-based foodstuffs and the second one at $8 \mathrm{~h}$ following isoflavone intake, leading to a mean $T_{\max }$ of 6.9 (SD 3.4) and 6.1 (SD 5.0) $\mathrm{h}$ for capsules and cheese respectively. In the case of genistein, $T_{\max }$ values were 6.7 (SD 4.0) and 4.6 (SD 2.4) for capsules and cheese respectively. Pharmacokinetic analysis of the plasma concentration-time curves showed that the 
NS British Journal of Nutrition

Table 2. Isoflavone content in diet supplements based on soya and freely available on the European market

\begin{tabular}{|c|c|c|c|c|c|c|c|c|}
\hline & Soy based supplements & Manufacturer & $\begin{array}{l}\text { Claimed dose } \\
(\mathrm{mg})\end{array}$ & $\begin{array}{c}\text { Genistein } \\
\text { (mg per tablet) }\end{array}$ & $\begin{array}{c}\text { Daidzein } \\
\text { (mg per tablet) }\end{array}$ & $\begin{array}{l}\text { Total isoflavones } \\
\text { (mg per tablet) }\end{array}$ & $\begin{array}{l}\text { Recommended } \\
\text { prescription }\end{array}$ & $\begin{array}{l}\text { Intake per d } \\
(\mathrm{mg})\end{array}$ \\
\hline 1 & Anacaps & Ducray & $?$ & $0.76 \pm 0.07$ & $0.63 \pm 0.07$ & $1.39 \pm 0.15$ & 2 & $2.8 \pm 0.30$ \\
\hline $2 \ddagger$ & Biopause & Monin Chanteaud & $?$ & $1.4 \pm 0.2$ & $1 \cdot 0 \pm 0.1$ & $2.45 \pm 0.22$ & 2 & $4.9 \pm 0.44$ \\
\hline 3 & Biopause Fort & Monin Chanteaud & $?$ & $0.4 \pm 0.1$ & $1.50 \pm 0.2$ & $1.9 \pm 0.22$ & 2 & $3.8 \pm 0.44$ \\
\hline $4 \ddagger$ & Bioptimum Soja & Boiron & $?$ & $3.1 \pm 0.5$ & $9 \pm 1.3$ & $12.1 \pm 0.55$ & 2 & $24 \cdot 2 \pm 1 \cdot 10$ \\
\hline 5 & Compléal & Besins Int. Nutraceutique & 45 & $28.5 \pm 2.9$ & $13.9 \pm 0.7$ & $42.4 \pm 0.77 \dagger$ & 2 & $84.8 \pm 1.5$ \\
\hline 6 & Cybestron & Vital & 250 & $0.07 \pm 0.01$ & $<0.001$ & $0.07 \pm 0.01$ & 1 & $0.07 \pm 0.01$ \\
\hline $7 \ddagger$ & Efodyne & Yves Ponroy & 20 & $1.5 \pm 0.2$ & $6.7 \pm 1.0$ & $8.20 \pm 0.45$ & 1 & $8.20 \pm 0.45$ \\
\hline $8 \ddagger$ & Elugyne & Dolisos & $?$ & $2.7 \pm 0.4$ & $10 \cdot 6 \pm 1 \cdot 6$ & $13.30 \pm 0.58$ & 1 & $13.30 \pm 0.58$ \\
\hline 9 & Estrofort & Rotapharm & 60 & $21.5 \pm 1.9$ & $10 \cdot 0 \pm 0.14$ & $31.5 \pm 0.58^{\star}$ & 1 & $31.5 \pm 0.58$ \\
\hline $10 \ddagger$ & Estronat & Lescuyer & 40 & $6.6 \pm 1.0$ & $6.5 \pm 1.0$ & $13 \cdot 10 \pm 0.58$ & 3 & $39 \cdot 3 \pm 1.74$ \\
\hline $11 \ddagger$ & Evestrel & Theramex MERCK & 37.5 & $11.6 \pm 1.7$ & $9 \cdot 2 \pm 1 \cdot 4$ & $20.80 \pm 0.72^{\star}$ & 2 & $41.6 \pm 1.44$ \\
\hline 12 & Evestrel jour/nuit & Théramex MERCK & 37.5 & $20.4 \pm 2.3$ & $6.6 \pm 0.3$ & $27 \cdot 0 \pm 0.66^{*}$ & 2 & $54 \cdot 0 \pm 1 \cdot 22$ \\
\hline 13 & Féminibiane & Pilege La Micronutrition & 25 & $6.5 \pm 0.2$ & $5.2 \pm 0.2$ & $11.7 \pm 0.26^{*}$ & 1 & $11.7 \pm 0.26$ \\
\hline $14 \ddagger$ & Feminine & Medikem & $?$ & $3.3 \pm 0.5$ & $1.5 \pm 0.2$ & $4.8 \pm 0.34$ & 2 & $9.6 \pm 0.68$ \\
\hline 15 & Féminité Soja D3 & CEnobiol & 20 & $4.2 \pm 0.4$ & $5.8 \pm 0.7$ & $10.0 \pm 0.43^{*}$ & 2 & $20.0 \pm 0.86$ \\
\hline $16 \ddagger$ & Gydrelle & Iprad Santé & 45 & $4.5 \pm 0.7$ & $13 \cdot 3 \pm 2$ & $17.7 \pm 0.67$ & 2 & $35.0 \pm 1.34$ \\
\hline 17 & Gydrelle phyto fort & Iprad Santé & 90 & $17.9 \pm 1.4$ & $9.4 \pm 0.2$ & $27.3 \pm 0.52$ & 1 & $27 \cdot 3 \pm 0.52$ \\
\hline $18 \ddagger$ & Gynalpha fort & CCD & 76 & $28 \cdot 6 \pm 4.3$ & $64 \cdot 2 \pm 9 \cdot 6$ & $92 \cdot 8 \pm 15 \cdot 2$ & 1 & $92.8 \pm 15 \cdot 2$ \\
\hline $19 \ddagger$ & Gynalpha & CCD & 38 & $12 \cdot 1 \pm 1 \cdot 8$ & $15 \cdot 0 \pm 2 \cdot 2$ & $27.1 \pm 0.82^{*}$ & 2 & $54.2 \pm 1.64$ \\
\hline 20 & Gynalpha plus & $\mathrm{CCD}$ & 38 & $12 \cdot 0 \pm 0.7$ & $10 \cdot 1 \pm 0.8$ & $22.1 \pm 0.5^{*}$ & 1 & $22.1 \pm 0.5$ \\
\hline $21 \ddagger$ & Gynosoya & Codifra & 37.5 & $27 \cdot 0 \pm 4 \cdot 0$ & $7.4 \pm 1.1$ & $34.4 \pm 0.92 \dagger$ & 2 & $68.8 \pm 1.84$ \\
\hline 22 & Inneov fermeté & Inneov & $16 \cdot 6$ & $4.9 \pm 0.7$ & $3.9 \pm 0.4$ & $8.8 \pm 0.43^{*}$ & 2 & $17.6 \pm 0.86$ \\
\hline 23 & IF super concentrés & Solgar- SoyLife & 38 & $5.1 \pm 0.3$ & $18.5 \pm 3.3$ & $23.6 \pm 0.77^{\star}$ & 1 & $23.6 \pm 0.77$ \\
\hline 24 & Isoflavone de soja & Vitarmonyl & 20 & $10.7 \pm 1.9$ & $5.0 \pm 0.6$ & $15.7 \pm 0.65^{*}$ & 2 & $31.4 \pm 1.30$ \\
\hline 25 & Isopro & Eko Bio & 100 & $4.4 \pm 0.1$ & $21 \cdot 1 \pm 1 \cdot 7$ & $25.5 \pm 0.55$ & 1 & $25.5 \pm 0.55$ \\
\hline $26 \ddagger$ & Isoyam & Starvital & 10 & $1.7 \pm 0.2$ & $1.5 \pm 0.2$ & $3.2 \pm 0.26$ & 3 & $9.6 \pm 0.78$ \\
\hline $27 \ddagger$ & Macasoyam & Fenioux & 15 & $2.2 \pm 0.3$ & $4.8 \pm 0.7$ & $7.0 \pm 0.41$ & 6 & $42 \cdot 0 \pm 2.46$ \\
\hline 28 & Ménocomplexe & Biotechnie & 35 & $18.3 \pm 0.2$ & $9.3 \pm 0.2$ & $27.6 \pm 0.26^{*}$ & 2 & $55.2 \pm 0.52$ \\
\hline 29 & Ménoflore & Floressance & $?$ & $<0.001$ & $<0.001$ & $<0.001$ & 3 & $<0.003$ \\
\hline $30 \ddagger$ & Menolig & Vichy & 20 & $11.3 \pm 1.7$ & $5.6 \pm 0.8$ & $16.9 \pm 0.65^{*}$ & 4 & $67 \cdot 6 \pm 2 \cdot 60$ \\
\hline 31 & Ménopause & Juvamine & $?$ & $2.7 \pm 0.1$ & $1.2 \pm 0.1$ & $3.9 \pm 0.18$ & 4 & $15.6 \pm 0.72$ \\
\hline $32 \ddagger$ & Oligoforme 50 & IDO & $?$ & $0.4 \pm 0.06$ & $0.2 \pm 0.03$ & $0.6 \pm 0.12$ & 4 & $2.4 \pm 0.48$ \\
\hline 33 & Pausanorm & Alkimson & 50 & $0.04 \pm 0.04$ & $0.2 \pm 0.02$ & $6.2 \pm 0.55 \S$ & 1 & $0.24 \pm 0.04$ \\
\hline $34 \ddagger$ & Preluzelle & LPF & 30 & $8.6 \pm 1.3$ & $10.7 \pm 1.6$ & $19.4 \pm 0.70^{*}$ & 2 & $38.8 \pm 1.4$ \\
\hline $\begin{array}{l}3++ \\
35\end{array}$ & Promensil & Novogen & 40 & $0.7 \pm 0.02$ & $0.3 \pm 0.005$ & $44 \cdot 4 \pm 2 \cdot 16 \S$ & 1 & $1.0 \pm 0.06$ \\
\hline $36 \ddagger$ & Phytofemme (iso) & Superdiet & 20 & $4.9 \pm 0.7$ & $4 \pm 0.6$ & $8.9 \pm 0.47$ & 2 & $17.8 \pm 0.94$ \\
\hline 37 & Phytosoya & Arkopharma & 17.5 & $1.7 \pm 0.2$ & $7.1 \pm 0.9$ & $8 \cdot 7 \pm 1.0^{*}$ & 2 & $17.4 \pm 2.00$ \\
\hline $38 \ddagger$ & Sojacal & Novagyn & $?$ & $9.5 \pm 1.4$ & $6.3 \pm 0.9$ & $15.8 \pm 0.62$ & 2 & $31.6 \pm 1.24$ \\
\hline 39 & Sojalia & Biocentury & 17.5 & $6.6 \pm 0.5$ & $3.7 \pm 0.7$ & $10.0 \pm 0.45^{\star}$ & 2 & $20.0 \pm 0.90$ \\
\hline $40 \ddagger$ & Sojamag & Novagyn & $?$ & $10.7 \pm 1.6$ & $6.1 \pm 0.9$ & $16.8 \pm 0.65$ & 2 & $33.6 \pm 1.30$ \\
\hline 41 & Sojapause & Oligo pharma & 35 & $14.7 \pm 0.4$ & $7.2 \pm 0.25$ & $21.9 \pm 0.33^{*}$ & 2 & $43.8 \pm 0.66$ \\
\hline $42 \ddagger$ & Sojyam & Tonipharm & $?$ & $5.9 \pm 0.9$ & $2.8 \pm 0.4$ & $8.7 \pm 0.47$ & 3 & $26 \cdot 1 \pm 1 \cdot 41$ \\
\hline 43 & Soya femme 24 jour & Forté Pharma & 25 & $12.7 \pm 0.5$ & $9 \cdot 8 \pm 1 \cdot 2$ & $22.5 \pm 0.53 \dagger$ & 1 & $22.5 \pm 0.53$ \\
\hline 44 & Soya femme 24 nuit & Forté Pharma & 25 & $13.0 \pm 0.5$ & $9.9 \pm 1.9$ & $22.9 \pm 0.63 \dagger$ & 1 & $22.9 \pm 0.63$ \\
\hline 45 & Soya Ménopause & Nutrisanté & 20 & $9.2 \pm 0.9$ & $4.9 \pm 0.5$ & $14.1 \pm 0.48^{\star}$ & 2 & $28.2 \pm 0.96$ \\
\hline $46 \ddagger$ & Soyolig & Vichy & 37.5 & $11.9 \pm 1.8$ & $6 \cdot 7 \pm 1$ & $18.6 \pm 0.68^{*}$ & 2 & $37.2 \pm 1.36$ \\
\hline 47 & Thalassovital & Diététique et Santé & 31 & $2 \cdot 1 \pm 0.1$ & $7.4 \pm 0.5$ & $9.5 \pm 0.32$ & 1 & $9.5 \pm 0.32$ \\
\hline 48 & Ymea & Chefaro-Ardeval & $?$ & $0.7 \pm 0.02$ & $2.5 \pm 0.04$ & $3 \cdot 2 \pm 0.10$ & 2 & $6.4 \pm 0.20$ \\
\hline 49 & Ysoflavone complexe & Ysonut & 100 & $5.0 \pm 0.5$ & $12.9 \pm 0.5$ & $17.9 \pm 0.58$ & 2 & $36 \cdot 8 \pm 1 \cdot 16$ \\
\hline
\end{tabular}

"Values resulting from ELISA assessment are less than $50 \%$ of the claimed values of isoflavones. The differences between claim doses and assessment doses may represent the weight of sugar conjugated with isoflavones. †Claimed values are similar to the ELISA assessment values of isoflavones. Manufacturers have ever indicated the isoflavones in aglycone equivalent.

$\S$ High values are due to the presence of another isoflavone, the biochanin A (data not shown). 
Table 3. Isoflavone concentration of solid matrix (A) or liquid matrix (B) soya-based foodstuffs, available on the European market

\begin{tabular}{|c|c|c|c|c|c|c|c|}
\hline & Soya-based foodstuffs & Manufacturer & Portion (g) & Genistein (mg per g) & Daidzein (mg per g) & Total isoflavone ( $\mathrm{mg}$ per $\mathrm{g}$ ) & Intake per portion (mg) \\
\hline \multicolumn{8}{|l|}{ (A) } \\
\hline 1 & Croq soja provençal & Gerblé & 100 & $0.32 \pm 0.03$ & $0.22 \pm 0.02$ & $0.54 \pm 0.13$ & $54 \cdot 1 \pm 13.0$ \\
\hline 2 & Croque tofou & Soy & 100 & $0.29 \pm 0.02$ & $0.31 \pm 0.02$ & $0.60 \pm 0.12$ & $59.83 \pm 12.0$ \\
\hline 3 & Hyperproteinés gourmand & Slimexcell & 46 & $0.45 \pm 0.06$ & $0.27 \pm 0.03$ & $0.73 \pm 0.17$ & $33.4 \pm 7.8$ \\
\hline 4 & Le Tartimi & Le Sojami & 40 & $0.34 \pm 0.03$ & $0.28 \pm 0.02$ & $0.62 \pm 0.13$ & $24.8 \pm 5 \cdot 2$ \\
\hline 5 & Senjà & Danone & 100 & $0.09 \pm 0.01$ & $0.08 \pm 0.02$ & $0.17 \pm 0.01$ & $17 \cdot 13 \pm 1 \cdot 0$ \\
\hline 6 & Sojasun cuisine & Sojasun & 20 & $0.13 \pm 0.01$ & $0.12 \pm 0.01$ & $0.25 \pm 0.08$ & $4.91 \pm 1.6$ \\
\hline 7 & Soja dessert chocolat & Bjorg & 100 & $0.04 \pm 0.01$ & $0.03 \pm 0.01$ & $0.08 \pm 0.01$ & $7.8 \pm 1.0$ \\
\hline 8 & Tofu nature & Bjorg & 125 & $0.42 \pm 0.01$ & $0.34 \pm 0.01$ & $0.77 \pm 0.08$ & $95 \cdot 8 \pm 10 \cdot 3$ \\
\hline 9 & Yoghourt & Soja Douceur & 120 & $0.13 \pm 0.01$ & $0.13 \pm 0.01$ & $0.26 \pm 0.03$ & $30.5 \pm 3.6$ \\
\hline 10 & Chocolate cream & Biosoy & 100 & $0.10 \pm 0.01$ & $0.11 \pm 0.01$ & $0.21 \pm 0.02$ & $20 \cdot 6 \pm 2 \cdot 0$ \\
\hline 11 & Sausages & Soycisses & 90 & $0.26 \pm 0.01$ & $0.23 \pm 0.02$ & $0.49 \pm 0.05$ & $44 \cdot 1 \pm 4.5$ \\
\hline 12 & Tofu pancake & Tossolia & 100 & $0.23 \pm 0.01$ & $0.15 \pm 0.01$ & $0.38 \pm 0.04$ & $38 \cdot 3 \pm 4 \cdot 0$ \\
\hline 13 & Vanilla Cream & Sokoya & 46 & $0.29 \pm 0.02$ & $0.19 \pm 0.01$ & $0.48 \pm 0.05$ & $22 \cdot 1 \pm 2 \cdot 3$ \\
\hline 14 & Soup & Sokoya & 46 & $0.22 \pm 0.01$ & $0.14 \pm 0.01$ & $0.36 \pm 0.04$ & $16.5 \pm 1 \cdot 8$ \\
\hline \multirow[t]{2}{*}{15} & Breakfast & Sokoya & 46 & $0.19 \pm 0.01$ & $0.10 \pm 0.01$ & $0.28 \pm 0.03$ & $13 \cdot 0 \pm 1 \cdot 4$ \\
\hline & Soya-based foodstuffs & Manufacturer & Portion (ml) & Genistein ( $\mu \mathrm{g}$ per $\mathrm{ml}$ ) & Daidzein ( $\mu \mathrm{g}$ per $\mathrm{ml}$ ) & Total isoflavone ( $\mu \mathrm{g}$ per $\mathrm{ml}$ ) & Intake per portion $(\mathrm{mg})$ \\
\hline \multicolumn{8}{|l|}{ (B) } \\
\hline 1 & Tonyu, chocolate flavoured & Bjorg & 250 & $55.8 \pm 11.7$ & $31.4 \pm 0.4$ & $87 \cdot 2 \pm 11.4$ & $21 \cdot 8 \pm 2 \cdot 9$ \\
\hline 2 & Biosoy & Soy & 250 & $143 \cdot 3 \pm 40 \cdot 2$ & $138 \cdot 2 \pm 21 \cdot 3$ & $281.5 \pm 25.4$ & $70.4 \pm 6.4$ \\
\hline 3 & Soymilk, vanilla flavoured & Regain & 250 & $82.7 \pm 8.5$ & $46 \cdot 3 \pm 7 \cdot 0$ & $129 \cdot 0 \pm 15 \cdot 6$ & $32.3 \pm 3.9$ \\
\hline 4 & Soya drink & Sojasun & 250 & $78 \cdot 3 \pm 20 \cdot 6$ & $63 \cdot 7 \pm 1 \cdot 8$ & $142 \cdot 0 \pm 3.9$ & $35.5 \pm 1.0$ \\
\hline 5 & Biosoya & Provamel & 250 & $51.5 \pm 11.0$ & $31.7 \pm 1.7$ & $83 \cdot 2 \pm 12 \cdot 7$ & $20 \cdot 8 \pm 3 \cdot 2$ \\
\hline
\end{tabular}




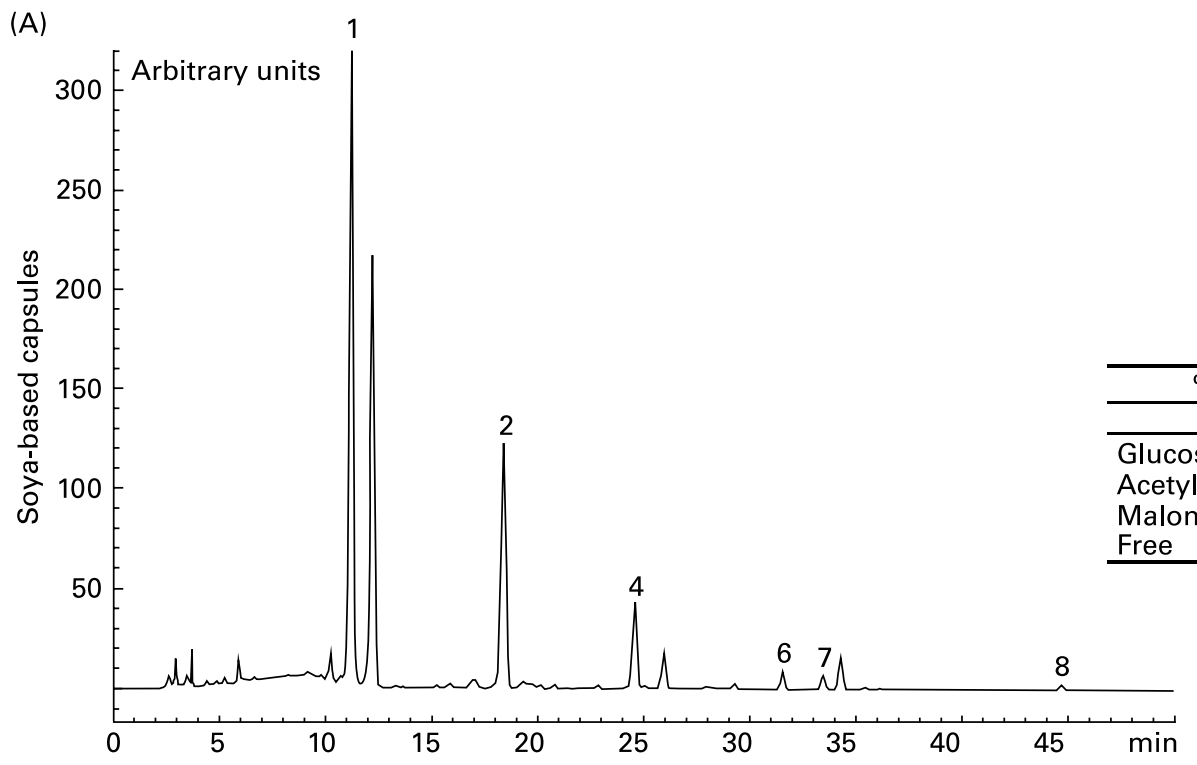

(B)

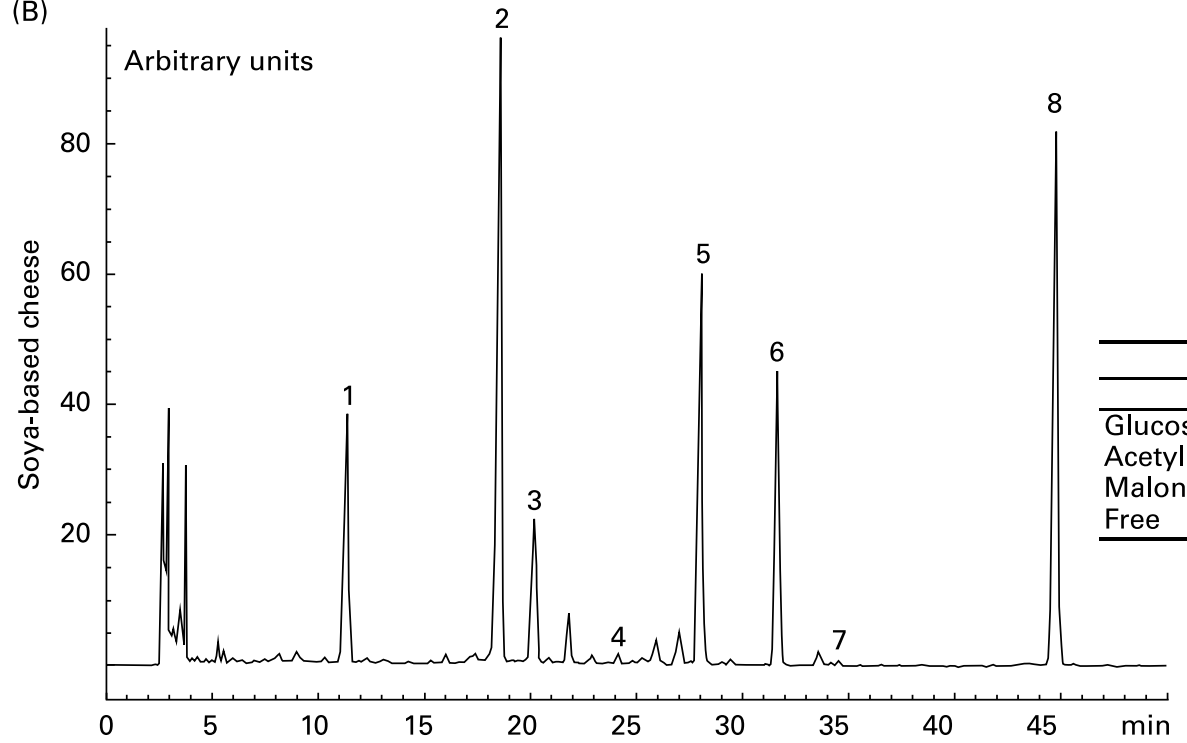

Fig. 1. HPLC chromatographic profiles of soya-based capsules (A) and soya-based cheese (B) ingested by the twelve volunteers. Peak identification: 1. daidzin; 2. genistin; 3. malonyl-daidzin; 4. acetyl-daidzin; 5. malonyl-genistin; 6. daidzein; 7. acetyl-genistin; 8. genistin. Tables represent the percentage of each isoflavone and their associated glycosides found in the two soya-based products. For details of subjects and procedures, see Subjects and methods.

elimination $T_{\frac{1}{2}}$ of genistein was 15.3 (SD 7.4) and 11.9 (SD 4.4) $\mathrm{h}$ for capsules and cheese respectively. In the present study, no equol producers were found within the recruited population of volunteers.

Comparison of isoflavone bioavailability between soya-based cheese and soya-based capsules

The mean pharmacokinetic parameters of isoflavones and the $P$ values of the two soya-based products are shown in Table 4 . Despite the equal amount of total isoflavone intake, the bioavailability varied according to the two soya-based products used. The adjusted Cmax of daidzein from soya-based cheese is significantly lower than that from soya-based capsules $(P=0 \cdot 002)$. Similarly, the adjusted $C_{\max }$ of genistein was significantly lower for cheese than that measured for capsules $(P=0.002)$. The adjusted $\mathrm{AUC}_{0 \rightarrow \infty}$ of genistein was 171.3 (SD 47.2) and 331.7 (SD 155.5) $\mathrm{ng} / \mathrm{ml}$ per $\mathrm{h}$ per $\mathrm{mg}$ ingested for cheese and capsules, respectively, and were significantly different $(P=0.002)$.

Moreover the adjusted $\mathrm{AUC}_{0 \rightarrow \infty}$ for both the isoflavones in cheese was $1.27 \mu \mathrm{mol} / \mathrm{l}$ per $\mathrm{h}$ per $\mathrm{mg}$ isoflavones ingested (0.63 (SD 0.17) and 0.64 (SD 0.29) $\mu \mathrm{mol} / \mathrm{l}$ per $\mathrm{h}$ per $\mathrm{mg}$, for genistein and daidzein respectively). On the other hand, the 
(A)

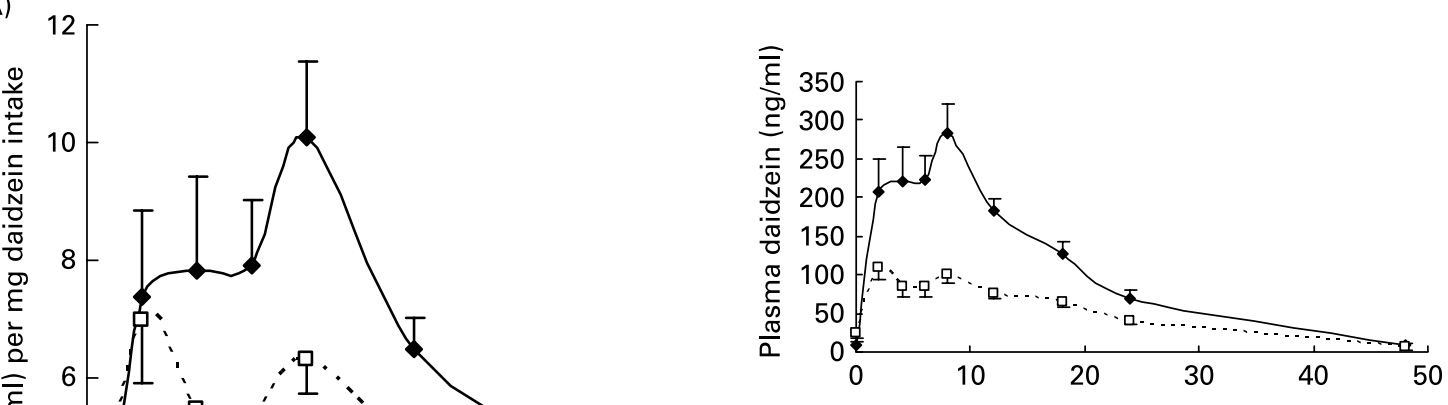

0

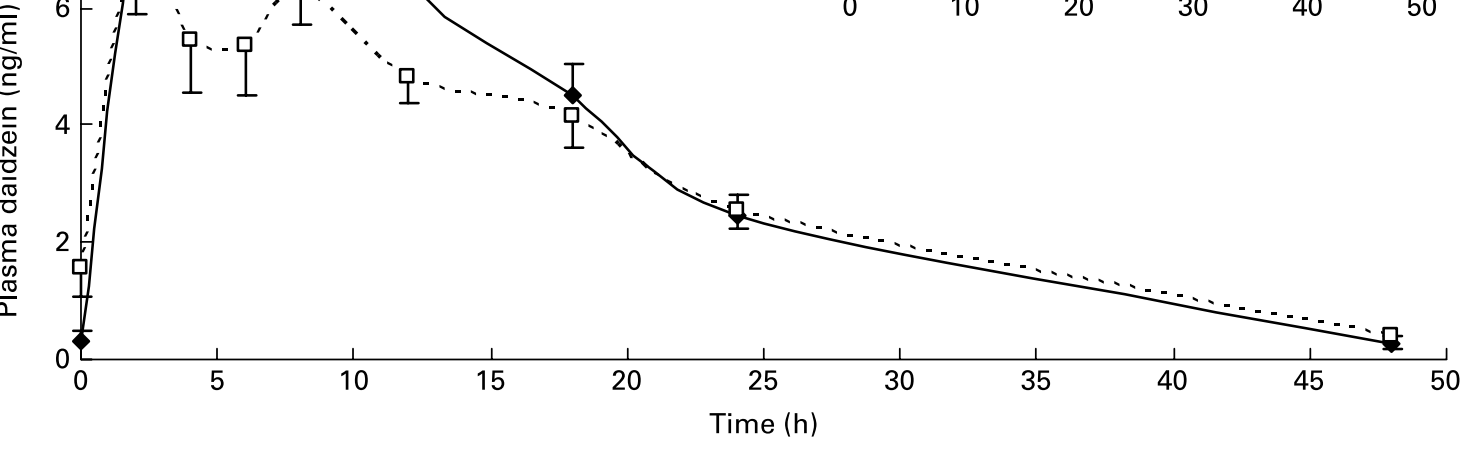

(B)

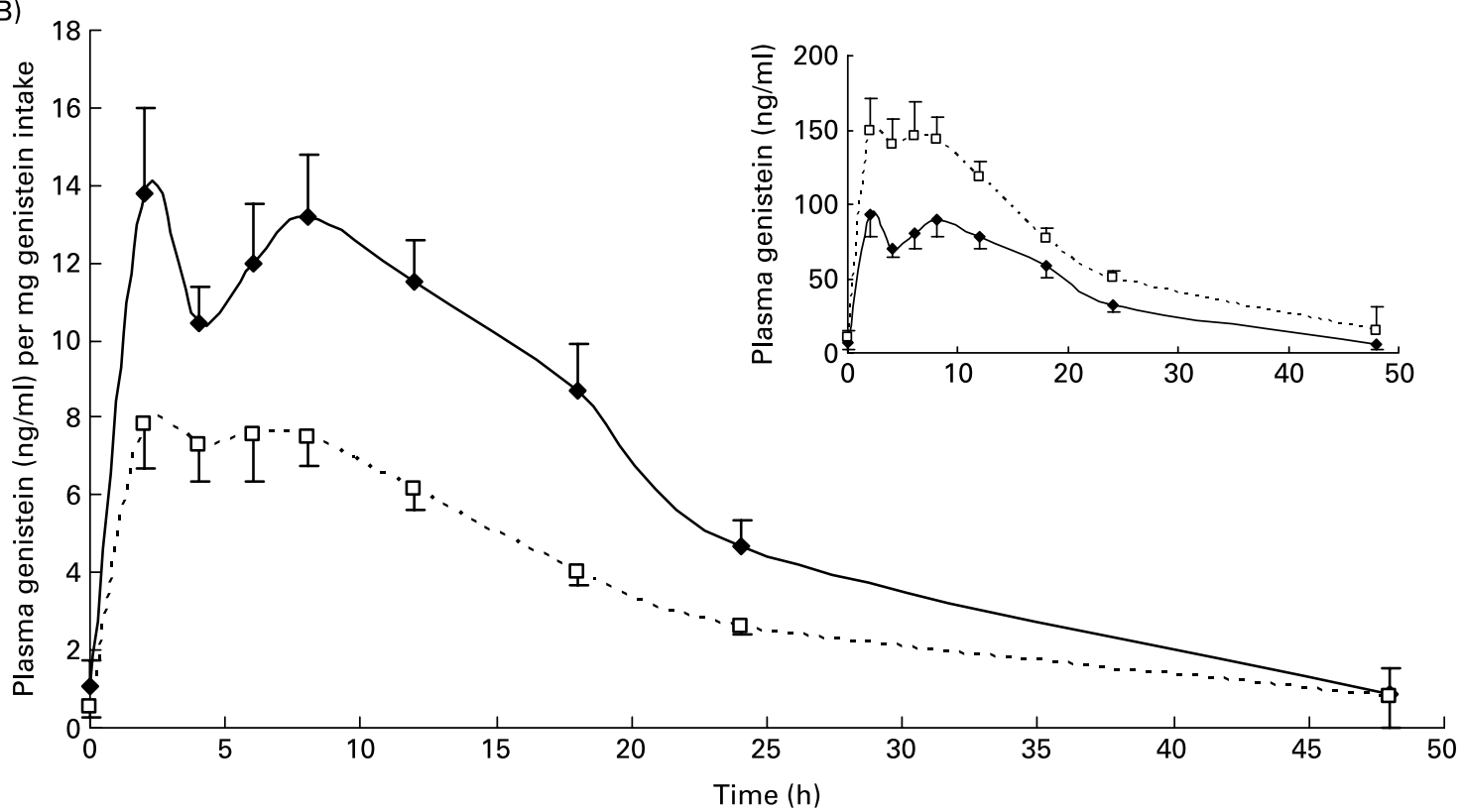

Fig. 2. Time-course of plasma daidzein (A) and genistein (B) concentrations, adjusted to the intake of each isoflavone, in twelve volunteers following soya-based cheese $(\square)$ or soya-based capsules $(\bullet)$ intake. Values are means with their standard errors of the mean. Graphics at the top represented time-course of plasma isoflavones without the dose intake adjustment. For details of subjects and procedures, see Subjects and methods.

globally adjusted $\mathrm{AUC}_{0 \rightarrow \infty}$ for capsules is $1.92 \mu \mathrm{mol} / \mathrm{l}$ per $\mathrm{h}$ per $\mathrm{mg}$ ingested (1.23 (SD 0.58) and 0.69 (SD 0.22) $\mu \mathrm{mol} / \mathrm{l}$ per $\mathrm{h}$ per $\mathrm{mg}$ for genistein and daidzein respectively), leading to an adjusted $\mathrm{AUC}_{0 \rightarrow \infty}$ ratio of 1.50 between the two soyabased products.

\section{Urinary excretion of isoflavones}

From 0 to $24 \mathrm{~h}$, the daidzein excretion profile was a bell-curve shaped with a maximal excretion peak between 6 and $12 \mathrm{~h}$ (Fig. 3(A)). For capsules and cheese respectively, 82.6
(SD 6.1) \% and 65.4 (SD 7.2) \% ingested daidzein was eliminated during the study period. The genistein excretion profile is similar to that observed for daidzein (Fig. 3(B)). For the capsules and cheese respectively, 46.3 (SD 7.4) and 26.9 (SD 4.6) $\%$ of the total ingested genistein was excreted in urine. Whatever the isoflavone ingested, the total urinary excretion was higher for the intake of capsules than that for the intake of cheese. Particular differences appeared in the urinary excretion of daidzein during the $6-12 \mathrm{~h}$ and $12-18 \mathrm{~h}$ periods and in the urinary excretion of genistein during the $6-12 \mathrm{~h}$ period. 


\section{Discussion}

To assess fully the dietary impact of phyto-oestrogens on the health of the population, it is necessary to know their concentrations in the foods consumed and their circulating concentrations following intake.

Isoflavones are mainly present as glucoside conjugates in most commercially available soya-containing products ${ }^{28}$. However, isoflavones are hydrolysed as a free form before their intestinal absorption. Even if a conjugation with glucuronide or sulphate takes place during the metabolism of isoflavones, the isoflavone molecule still remains the active party due to its ability to bind to the oestrogen receptors ${ }^{29}$ after entering the target cells. Provider claims often take into account the whole weight of the isoflavone molecules, including sugar moiety, which explains the most frequent discrepancies observed between the provider claims and the data measured in our laboratory ${ }^{24}$. The weight of the glucose unit is approximately $40 \%$ of the total glucoside weight and in the case of malonyl- and acetyl-forms the weight of the inactive sugar moiety increases up to $50 \%$. In addition, the relative proportions of each glycoside form are known to be influenced by the extraction steps taken before analysis ${ }^{30}$. Consequently, as already suggested by Nurmi et al., Erdman et al., the French Food Safety Agency and Messina et al., the recommended way to express isoflavone content in soya food products is to use the aglycone weight ${ }^{12,31-33}$.

The present study presents isoflavone content data in a selection of foodstuffs, which could be included in an existing phyto-oestrogen database ${ }^{34}$. These food products represent only a small proportion of the 'Western' soya-based products freely available on the market. In France, the isoflavone intake for a traditional meal was estimated to be of the order of $22.1 \mu \mathrm{g}$, from the database published by the French Food Safety Agency ${ }^{32}$. However, more isoflavones could be ingested by consuming several soya-based products, such as those presented in the current study. Regularly consumed, these products can induce non-negligible isoflavone concentrations in plasma and may lead to physiological effects.

Although, there has been interest in the potential risks and benefits of consuming diets enriched in soya isoflavones, to date, relatively limited research has been conducted comparing apparent bioavailability of isoflavones contained in soya-based supplements or in soya-based food and concentrations reached in blood and urine. The soya-based products selected for our clinical trial represented two different nutritional forms of isoflavone intake, since one is a food supplement, i.e. taken daily and several times throughout the day, and the other is a soya-based cheese, eaten occasionally during a meal. In all cases, to exert their biological effects, isoflavones have to be bioavailable.

The aim of the present clinical study was to investigate the concentrations of isoflavones reached in serum and urine in twelve healthy male volunteers given an oral dose of two different food products containing $35 \mathrm{mg}$ isoflavones, equivalent aglycone. Since both soya-based products consist of different proportions of daidzein and genistein (approximately 3:4 for cheese and 4:1 for capsules), the total quantity of isoflavones was first considered. Daidzein and genistein contents in soya food can vary and depend on the raw material and processing conditions used to produce a particular food product. In each type of soya food, there are different forms 
(A)

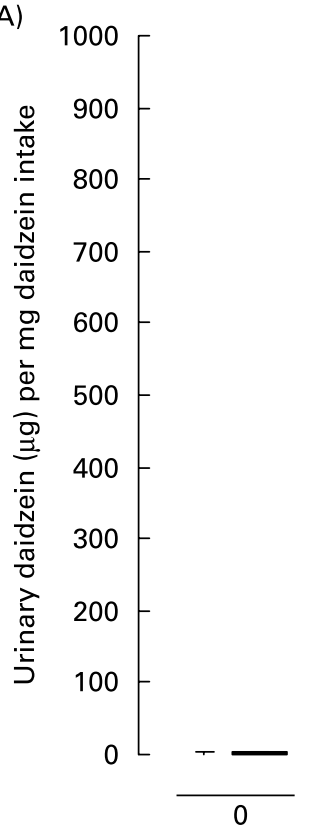

(B)

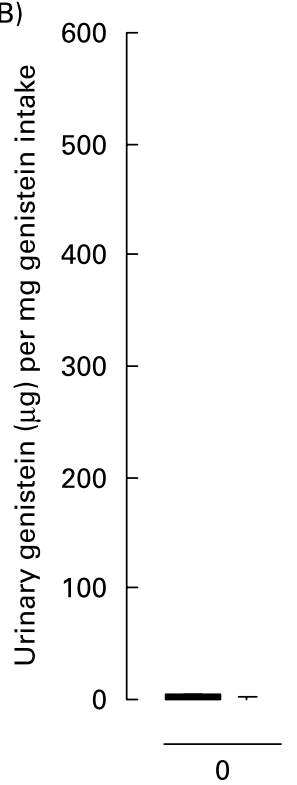

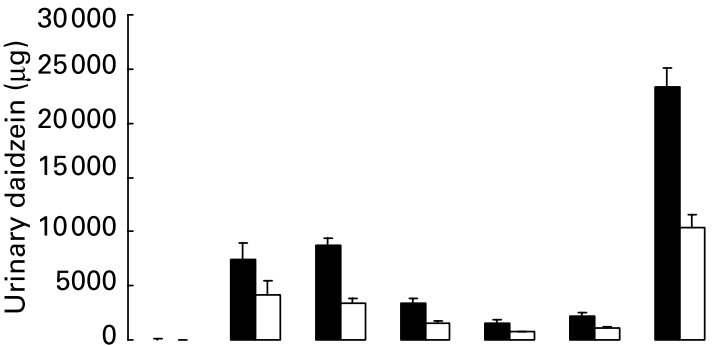
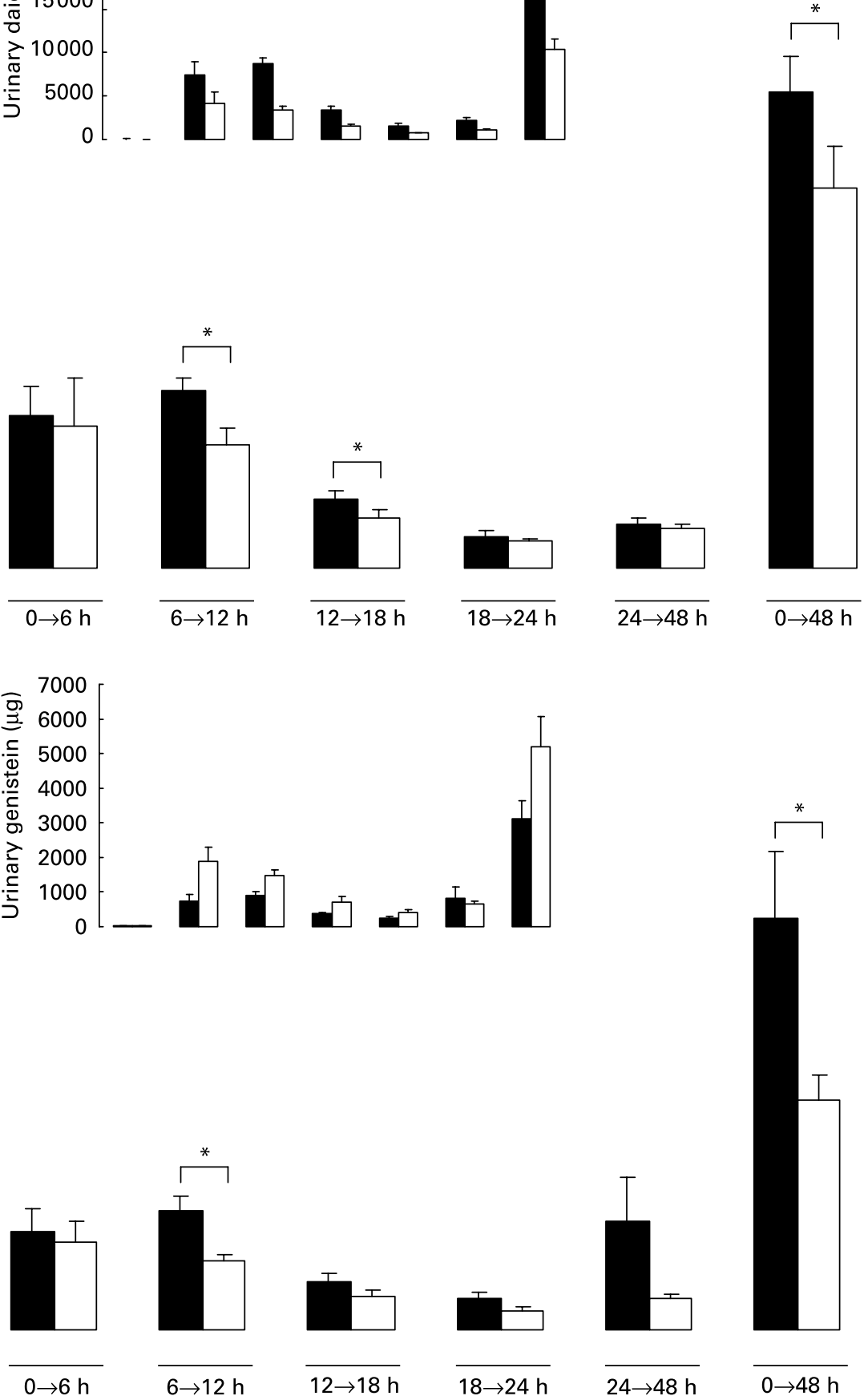

Fig. 3. Urinary daidzein (A) and genistein (B) excretion profiles following the ingestion of capsules ( $\square$ ) or cheese ( $\square$ ), adjusted to the intake of each isoflavones. Results are expressed as means with their standard errors of the mean. Histograms at the top represented values without the dose intake adjustment. For details of subjects and procedures, see Subjects and methods.

of isoflavones in differing amounts. Based on the equivalent dose of isoflavones, the administration of different soya foods has shown no difference in particular isoflavone bioavailability $^{35}$. Even though the metabolism is similar, no competition phenomenon of absorption, metabolism and elimination of these molecules has ever been reported.
Furthermore, the total quantity of isoflavones is lower than those used to describe a small saturation effect in recent intervention studies ${ }^{36}$. Consequently, a normalization with the particular amount of each compound was performed to compare the pharmacokinetic parameters, as has classically been described by several authors ${ }^{18,20}$. 
The food supplement was initially chosen due to its high daidzein content. It was expected to lead to rather high equol concentrations in plasma. Unfortunately, out of the twelve volunteers, no one produced equol. This is not linked to the ELISA used in the present study since our previous studies reported an equol producer percentage close to that mentioned by other authors ${ }^{17,24,26}$. Furthermore, the design and the duration of the study cannot be responsible for this finding because a recent trial performed in the same conditions found four volunteers as equol producers out of a total of twelve volunteers ${ }^{17}$. Finally, according to criteria used to define equol producers, a previous clinical study did not find any equol producers among the twelve volunteers ${ }^{19}$. Since equol is produced by only 30 to $50 \%$ of the population, recruitment randomization alone may explain why no equol producers were involved in this trial.

In the present study, absorption and bioavailability parameters were in agreement with those classically described in literature. Moreover elimination $T_{\frac{1}{2}}$ was found to be longer than $T_{\frac{1}{2}}$ previously described in the literature ${ }^{3}$. With the present results, we confirmed longer elimination $T_{\frac{1}{2}}$, which had already been demonstrated in our previous study, in which the same soya-based capsules of Phytosoya ${ }^{\circledR}$ were ingested by healthy volunteers ${ }^{17}$. Moreover, Richelle et al. reported a similar elimination half-life of 17.8 (SD 2.7) $\mathrm{h}$ for ingested glycoside genistein ${ }^{16}$. With long elimination $T_{\frac{1}{2}}$, both genistein and daidzein are potentially able to accumulate in plasma, achieving a steady state level. Shorter $T_{\frac{1}{2}}$ do not allow this kind of kinetic pattern, except in the case of daily repeated ingestion. Such a practice is common to Asian people consuming soya foods as a natural component of the traditional diet ${ }^{37}$.

In any study dealing with bioavailability, the accuracy of pharmacokinetic parameters is dependent on obtaining sufficient plasma samples during the elimination phase. The $48 \mathrm{~h}$ point samples showed values near zero $\mathrm{ng} / \mathrm{ml}$, giving significance to this work. When pharmacokinetic parameter adjustment is performed with the real amounts ingested, the genistein concentrations are consistently higher in plasma than daidzein concentrations. The daidzein parameters of volume of distribution and a clearance rate were classically admitted to be higher and faster than those of genistein ${ }^{13}$ and can explain this observation. Furthermore, whatever the soya-based products ingested, the higher urinary excretion of daidzein compared with that of genistein can be observed, in accordance with literature ${ }^{17,38}$. The total urinary excretion of added isoflavones was higher for capsule intake than that of cheese intake, which is in accordance with the higher intestinal absorption of isoflavones contained in capsules.

The same total quantities of isoflavones, contained in two solid forms, were given to the subjects. Isoflavones from soya-based capsules were found to be more bioavailable than those from soya-based cheese, in spite of the differences in isoflavone composition between the two soya-based products. This result could be due to the high complexity of the cheese matrix, with its high content of lipids and proteins, which may limit intestinal absorption. Indeed, in such a matrix, isoflavones are expected to bind to other molecules by hydrogen or Van Der Waals bonds. Concomitantly, capsules are filled with a soya extract containing $10 \%$ isoflavones. Soya extracts result from a complex manufacturing process 5 , which may weaken or break the links between isoflavones and other molecular structures present in the food supplements. This could explain why the isoflavones contained in capsules were absorbed faster and in greater amounts than those contained in soya-based cheese, even though the two soya-based products do not present a similar conjugation pattern of isoflavones. Setchell et al. showed greater bioavailability of glucosides, as measured from the area under the curve, using single purified forms of isoflavone ${ }^{13}$. Izumi et al. found greater bioavailability of aglycones, on the basis of $C_{\max }{ }^{39}$, but they did not measure isoflavone concentrations between 6 and $24 \mathrm{~h}$, whereas Setchell et al. reported that the mean time to reach $C_{\max }$ was prolonged to $9 \mathrm{~h}$ after glycoside ingestion ${ }^{13}$. Two other clinical studies found no significant differences in the absorption efficiency for aglycones and glycosides ${ }^{16,40}$. No clear statement exists on the bioavailability of aglycone isoflavones and their glycosides forms. Recently, no difference was found in the bioavailability of isoflavones following a single ingestion of tempeh and textured vegetable protein in twenty-one young healthy males (16.29 (SD 4.65) and 19.79 (SD 7.87) $\mu \mathrm{mol} / \mathrm{h}$ per litre per $\mathrm{mg}$, respectively, for the area under the curve of daidzein normalized to $\mathrm{mg}$ ingested and 26.91 (SD 13.50) and 22.98 (SD 14.12) $\mu \mathrm{mol} / \mathrm{h}$ per litre per $\mathrm{mg}$, respectively, for the area under the curve of genistein normalized to $\mathrm{mg}$ ingested $)^{20}$. Tempeh is a fermented food that contains approximately $50 \%$ aglycone isoflavones, whereas textured vegetable protein contains less than $15 \%$ aglycone isoflavones. The conjugation patterns of these two products are similar to those of the soya-based cheese and the soya-based supplement used in the present clinical study. Consequently, the difference in the conjugation patterns of these two soya-based products may not induce differences in the bioavailability of isoflavones and thus lead us to interpret our results accordingly.

Interestingly, our observation of biphasic pharmacokinetic profiles of isoflavones occurring at $2 \mathrm{~h}$ (peak 1) and 4-8h (peak 2) after the soya-based product intake confirms previous studies ${ }^{9,40}$. The presence of two distinct peaks may indicate entero-hepatic recirculation as has already been suggested by several authors ${ }^{3,16,38}$. Furthermore, the presence of distinct peaks 1 and 2 may also define separate locations of preferred isoflavone absorption during digestion. Franke et al. suggested that the times at which peaks 1 and 2 occurred indicated that the location of uptake is respectively the small and the large intestine $^{41}$. In the case of soya-based beverage intake, the peaks occurred at $1 \mathrm{~h}$ and $4-6 \mathrm{~h}$. In the present study, the delay observed may be due to the time frame for solid matrices to reach the large intestine.

If we considered the $\mathrm{AUC}_{0 \rightarrow \infty}$ of both isoflavones, isoflavones contained in capsules were more bioavailable by $50.4 \%$ than those contained in soya-based cheese. A comparison with Asian populations could be attempted, using as a reference the study from Arai et $a l .{ }^{42}$. The isoflavone intake of 115 Japanese women was found to be $47.2 \mathrm{mg}$ per d, with an inter-individual variation reported from 12.0 to $118.9 \mathrm{mg}$. If soya-based cheese is assumed to be equivalent in value to other categories of soya-based Japanese food, $75.52 \mathrm{~g}$ soya-based cheese is necessary to mimic the mean Japanese isoflavone intake. Concerning soya-based supplements, this would be achieved with $33.04 \mathrm{mg}$ isoflavone, 
i.e. $3 \cdot 8$ capsules of Phytosoya ${ }^{\circledR}$. Moreover, the great variation in isoflavone intake, reported by Arai et $a l .{ }^{42}$, may be equivalent to a range of 8 to $83 \mathrm{mg}$ ingested by soya-based supplements. However, it must be kept in mind that this extrapolation is based on various hypotheses, which are far from being generally accepted. This parallel is merely theoretical and should be taken with caution.

In conclusion, assuming that isoflavone bioavailability is not influenced by the isoflavone conjugation pattern, the present work shows that isoflavones contained in the soyabased capsule are more bioavailable than those contained in soya-based cheese, after a single ingestion in twelve young male volunteers. Nevertheless, there is still little evidence to conclude that soya-based supplements are biologically active to date ${ }^{43}$ and further studies are needed to establish the effectiveness of soya isoflavones on health. The bioavailability of an active compound must be known before investigating the potential physiological effects. As a consequence, it seems crucial to understand the mechanism by which all these compounds are absorbed and to increase the knowledge on factors influencing their bioavailability.

\section{Acknowledgements}

The authors thank the volunteers who participated in the study, Danièle Lamazière, the dietitian who checked food composition for the study period, Jean-James Garreau for providing the cheese, Patricia Baile and Philippe Abbe for their kind assistance with the HPLC method and Christelle Rosier-Sala for her kind help in reviewing the manuscript. Special thanks to Russell Wallace for his kind help with the English language. This study was supported by Research Ministry of France, RARE Program $\mathrm{N}^{\circ} 03 \mathrm{P} 221$ and by the Région Aquitaine. Sébastien Vergne is the recipient of a fellowship (CIFRE $\mathrm{N}^{\circ} 856 / 2003$ ) from Arkopharma, Pharmaceutical Laboratories and National Association of Technical Research, Research Ministry of France.

\section{References}

1. Cassidy A, Albertazzi P, Lise Nielsen I, et al. (2006) Critical review of health effects of soyabean phyto-oestrogens in postmenopausal women. Proc Nutr Soc 65, 76-92.

2. Usui $\mathrm{T}$ (2006) Pharmaceutical prospects of phytoestrogens. Endocr J 53, 7-20.

3. Rowland I, Faughnan M, Hoey L, Wahala K, Williamson G \& Cassidy A (2003) Bioavailability of phyto-oestrogens. Br J Nutr 89, Suppl. 1, S45-S58.

4. Cassidy A, Bingham S \& Setchell KDR (1994) Biological effects of soy protein rich isoflavones on the menstrual cycle of premenopausal women. Am J Clin Nutr 60, 333-340.

5. Choi MS \& Rhee KC (2006) Production and processing of soybeans and nutrition and safety of isoflavone and other soy products for human health. $J$ Med Food 9, 1-10.

6. Xu X, Harris KS, Wang HJ, Murphy PA \& Hendrich S (1995) Bioavailability of soybean isoflavones depends upon gut microflora in women. $J$ Nutr 125, 2307-2315.

7. Piskula MK, Yamakoshi J \& Iwai Y (1999) Daidzein and genistein but not their glucosides are absorbed from the rat stomach. FEBS Lett 447, 287-291.

8. Day AJ, DuPont MS, Ridley S, Rhodes M, Rhodes MJ, Morgan MR \& Williamson G (1998) Deglycosylation of flavonoid and isoflavonoid glycosides by human small intestine and liver beta-glucosidase activity. FEBS Lett 436, 71-75.

9. Setchell KD, Brown NM, Zimmer-Nechemias L, Brashear WT, Wolfe BE, Kirschner AS \& Heubi JE (2002) Evidence for lack of absorption of soy isoflavone glycosides in humans, supporting the crucial role of intestinal metabolism for bioavailability. Am J Clin Nutr 76, 447-453.

10. Axelson M, Sjovall J, Gustafsson BE \& Setchell KD (1984) Soya - a dietary source of the non-steroidal oestrogen equol in man and animals. $J$ Endocrinol 102, 49-56.

11. Adlercreutz H, Musey PI, Fotsis T, Bannwart C, Wahala K, Makela T, Brunow G \& Hase T (1986) Identification of lignans and phytoestrogens in urine of chimpanzees. Clin Chim Acta 158, $147-154$.

12. Nurmi T, Mazur W, Heinonen S, Kokkonen J \& Adlercreutz H (2002) Isoflavone content of the soy based supplements. J Pharm Biomed Anal 28, 1-11.

13. Setchell KD, Brown NM, Desai P, Zimmer-Nechemias L, Wolfe BE, Brashear WT, Kirschner AS, Cassidy A \& Heubi JE (2001) Bioavailability of pure isoflavones in healthy humans and analysis of commercial soy isoflavone supplements. J Nutr 131, 1362S-1375S.

14. Busby MG, Jeffcoat AR, Bloedon LT, et al. (2002) Clinical characteristics and pharmacokinetics of purified soy isoflavones: single-dose administration to healthy men. Am J Clin Nutr 75, 126-136.

15. Bloedon LT, Jeffcoat AR, Lopaczynski W, et al. (2002) Safety and pharmacokinetics of purified soy isoflavones: single-dose administration to postmenopausal women. Am J Clin Nutr 76, 1126-1137.

16. Richelle M, Pridmore-Merten S, Bodenstab S, Enslen M \& Offord EA (2002) Hydrolysis of isoflavone glycosides to aglycones by beta-glycosidase does not alter plasma and urine isoflavone pharmacokinetics in postmenopausal women. $J$ Nutr 132, 2587-2592.

17. Vergne S, Titier K, Bernard V, et al. (2007) Bioavailability and urinary excretion of isoflavones in humans: effects of soy-based supplements formulation and equol production. J Pharm Biomed Anal 43, 1488-1494.

18. Anupongsanugool E, Teekachunhatean S, Rojanasthien N, Pongsatha S \& Sangdee C (2005) Pharmacokinetics of isoflavones, daidzein and genistein, after ingestion of soy beverage compared with soy extract capsules in postmenopausal Thai women. BMC Clin Pharmacol 5, 2.

19. de Pascual-Teresa S, Hallund J, Talbot D, Schroot J, Williams CM, Bugel S \& Cassidy A (2006) Absorption of isoflavones in humans: effects of food matrix and processing. $J$ Nutr Biochem 17, 257-264.

20. Cassidy A, Brown JE, Hawdon A, Faughnan MS, King LJ, Millward J, Zimmer-Nechemias L, Wolfe B \& Setchell KD (2006) Factors affecting the bioavailability of soy isoflavones in humans after ingestion of physiologically relevant levels from different soy foods. J Nutr 136, 45-51.

21. Kano M, Takayanagi $T$, Harada $K$, Sawada $S$ \& Ishikawa $F$ (2006) Bioavailability of isoflavones after ingestion of soy beverages in healthy adults. J Nutr 136, 2291-2296.

22. Murphy PA, Song T, Buseman G \& Barua K (1997) Isoflavones in soy-based infant formulas. J Agric Food Chem 45, 4635-4638.

23. Bennetau-Pelissero C, Le Houerou C, Lamothe V, Le Menn F, Babin P \& Bennetau B (2000) Synthesis of haptens and conjugates for ELISAs of phytoestrogens. Development of the immunological tests. J Agric Food Chem 48, 305-311.

24. Bennetau-Pelissero C, Arnal-Schnebelen B, Lamothe V, Sauvant P, Sagne JL, Verbruggen MA, Mathey J \& Lavialle $\mathrm{O}$ (2003) ELISA as a new method to measure genistein and daidzein in food and human fluids. Food Chemistry 82, $645-658$. 
25. Le Houerou C, Bennetau-Pelissero C, Lamothe V, Le Menn F, Babin P \& Bennetau B (2000) Syntheses of novel hapten-protein conjugates for production of highly specific antibodies to formononetin, daidzein and genistein. Tetrahedron 56, 295-301.

26. Mathey J, Lamothe V, Coxam V, Potier M, Sauvant P \& Pelissero CB (2006) Concentrations of isoflavones in plasma and urine of post-menopausal women chronically ingesting high quantities of soy isoflavones. J Pharm Biomed Anal 41, 957-965.

27. Grizzle JE (1965) The two-period change-over design and its use in clinical trials. Biometrics 21, 467-480.

28. Hubert J, Berger M \& Dayde J (2005) Use of a simplified HPLC-UV analysis for soyasaponin B determination: study of saponin and isoflavone variability in soybean cultivars and soy-based health food products. J Agric Food Chem 53, 3923-3930.

29. Muthyala RS, Ju YH, Sheng S, Williams LD, Doerge DR, Katzenellenbogen BS, Helferich WG \& Katzenellenbogen JA (2004) Equol, a natural estrogenic metabolite from soy isoflavones: convenient preparation and resolution of $\mathrm{R}$ - and $\mathrm{S}$ equols and their differing binding and biological activity through estrogen receptors alpha and beta. Bioorg Med Chem 12, $1559-1567$.

30. Verbruggen MA \& van Roojen JJM (2001) Analysis of isoflavones-results of a ring test. Fourth International Symposium on the Role of Soy in Preventing and Treating Chronic Disease, 4-7 November 2001. San Diego, California, USA.

31. Erdman JW Jr, Badger TM, Lampe JW, Setchell KD \& Messina M (2004) Not all soy products are created equal: caution needed in interpretation of research results. $J$ Nutr 134, 1229S-1233S.

32. AFSSA-AFSSAPS (French Food Safety Agency - French Health Products Safety Agency) (2005) The Safety and Benefits of dietary phytoestrogens - Recommendations. Joint AFSSAAFSSAPS expert consultation. AFSSA-AFSSAPS report ISBN 2-11-095443-4, Nancy, France, Imprimerie Blayec. Available at: http://www.afssa.fr.

33. Messina M, Nagata C \& Wu AH (2006) Estimated Asian adult soy protein and isoflavone intakes. Nutr Cancer 55, 1-12.
34. Ritchie MR, Cummings JH, Morton MS, Michael Steel C, Bolton-Smith C \& Riches AC (2006) A newly constructed and validated isoflavone database for the assessment of total genistein and daidzein intake. Br J Nutr 95, 204-213.

35. Xu X, Wang HJ, Murphy PA \& Hendrich S (2000) Neither background diet nor type of soy food affects short-term isoflavone bioavailability in women. $J$ Nutr 130, 798-801.

36. Setchell KD, Brown NM, Desai PB, Zimmer-Nechimias L, Wolfe B, Jakate AS, Creutzinger V \& Heubi JE (2003) Bioavailability, disposition, and dose-response effects of soy isoflavones when consumed by healthy women at physiologically typical dietary intakes. J Nutr 133, 1027-1035.

37. Yamamoto S, Sobue T, Kobayashi M, Sasaki S \& Tsugane S (2003) Soy, isoflavones, and breast cancer risk in Japan. J Natl Cancer Inst 95, 906-913.

38. Watanabe S, Yamaguchi M, Sobue T, Takahashi T, Miura T, Arai Y, Mazur W, Wahala K \& Adlercreutz H (1998) Pharmacokinetics of soybean isoflavones in plasma, urine and feces of men after ingestion of $60 \mathrm{~g}$ baked soybean powder (kinako). J Nutr 128, 1710-1715.

39. Izumi T, Piskula MK, Osawa S, Obata A, Tobe K, Saito M, Kataoka S, Kubota Y \& Kikuchi M (2000) Soy isoflavone aglycones are absorbed faster and in higher amounts than their glucosides in humans. J Nutr 130, 1695-1699.

40. Zubik L \& Meydani M (2003) Bioavailability of soybean isoflavones from aglycone and glucoside forms in American women. Am J Clin Nutr 77, 1459-1465.

41. Franke AA, Custer LJ \& Hundahl SA (2004) Determinants for urinary and plasma isoflavones in humans after soy intake. Nutr Cancer 50, 141-154.

42. Arai Y, Watanabe S, Kimira M, Shimoi K, Mochizuki R \& Kinae N (2000) Dietary intakes of flavonols, flavones and isoflavones by Japanese women and the inverse correlation between quercetin intake and plasma LDL cholesterol concentration. J Nutr 130, 2243-2250.

43. Faure ED, Chantre P \& Mares P (2002) Effects of a standardized soy extract on hot flushes: a multicenter, double-blind, randomized, placebo-controlled study. Menopause 9, 329-334. 